\title{
Pictogramas na Comunicação de Espaços Públicos: reflexões sobre o processo do design
}

\author{
Guilherme Ranoya \\ Doutorando em Meios e Processos \\ Audiovisuais, Mestre em Ciências \\ da Comunicação e Especialista em \\ Gestão Estratégica de Comunicação \\ Organizacional e Relações Públicas \\ pela Escola de Comunicação e Artes da \\ Universidade de São Paulo (ECA-USP). \\ Arquiteto formado pela Universidade \\ Mackenzie. \\ E-mail: ranoya@usp.br.
}

\section{Milton Raposo}

Especialista em Marketing Político e Propaganda Eleitoral pela ECA-USP. Estudou Design, Tipografia, Ilustração, Fotografia e Publicidade no St. Martins College of Art and Design. Bacharel em Publicidade e Propaganda pela UFPE. E-mail: miltonraposo@gmail.com.

\section{Silvio Koiti Sato}

Doutorando e Mestre em Ciências da Comunicação pela Escola de Comunicações e Artes da Universidade de São Paulo (ECA-USP). Publicitário formado pela ESPM-SP e especialista em Administração de Empresas pela EAESP/FGV-SP.

E-mail: silviosato@usp.br.

\section{Sandra Souza}

Doutora em Ciências da Comunicação pela Universidade de São Paulo, onde é e Livre-docente na Escola de Comunicações e Artes, Departamento de Relações Públicas, Propaganda e Turismo, orientadora do Programa de Pós-Graduação em Ciências da Comunicação e líder do grupo de pesquisa GEIC - Grupo de Estudos da Imagem em Comunicação.

E-mail: smrdsouz@usp.br.
Resumo: Este artigo tem o objetivo de provocar uma reflexão sobre o uso dos pictogramas na comunicação visual em espaços públicos. Baseado nas premissas do uso social do design gráfico, na criação centrada em necessidades do usuário e na interferência positiva das emoções na recepção e interpretação de mensagens normativas, utilizamos um exercício prático de tradução gráfica de mensagem verbal - desenvolvimento de pictogramas para uso adequado de instalações e equipamentos sanitários - para rever o processo metodológico de criação em design de comunicação e destacar o papel da pragmática nas escolhas de desenho e das mensagens sociais relevantes para uma comunidade. Destacamos, igualmente, o papel das emoções no processo comunicativo do design, tanto na produção dos estímulos visuais ambientais quanto em sua potencialidade para provocar, nos usuários, respostas a esses estímulos.

Palavras-chave: Design; pictogramas; higiene e saúde pública; banheiros; sinalização.

Abstract: This article is intended to provoke a reflection about the use of pictograms in visual communication in public spaces. Based on the assumptions of the social use of graphic design, creation centered on user's needs and the interference of positive emotions in the reception and interpretation of regulatory messages, we used a practical exercise to translate a graphic verbal message - the development of pictograms for appropriate use of sanitary equipment - to review the methodological process of creation in communication design and the role of pragmatics in the design choices and social messages relevant to a community. We emphasize also the role of emotions in the communicative process of design, both in the production of visual stimuli in their environment and potential to cause, in the users, responses to these stimuli.

Keywords: Design; pictograms; public health and hygiene; toilets; signage.

\section{Introdução}

Vivemos numa era imagética: estamos cercados por estímulos visuais, traduzidos no nosso cotidiano por composições estéticas as mais variadas, que mesclam cores, texturas e sombras com o uso de recursos tecnológicos a fim de criar novos efeitos visuais. Em muitas ocasiões, nós mesmos colaboramos para esta multiplicidade de estímulos, ao utilizarmos dispositivos tecnológicos cada vez mais populares como celulares, smartphones e tablets, que servem para registrar, fotografar, digitalizar, desenhar, colorir, tratar e transformar qualquer imagem, em qualquer lugar. A mesma tecnologia também facilita a rápida publicação e disseminação de 
novas imagens, colaborando para uma cultura visual cada vez mais fragmentada, focada em signos comunicativos que devem ser compreendidos e interpretados rapidamente.

O indivíduo, portanto, precisa lidar com uma quantidade muito maior de estímulos e informações atualmente, com a obrigação (ou necessidade) de processar e responder a estes estímulos e demandas de forma ágil e rápida - sempre com a sensação de que não há tempo a perder. Este ambiente contemporâneo é denominado de diversas maneiras, como pós-modernidade (HARVEY, 1992), modernidade líquida (BAUMAN, 2001) e hipermodernidade (LIPOVETSKY; SEBASTIER, 2004), entre outras nomenclaturas. Trata-se de um novo momento, mais complexo e amplo, caracterizado por mudanças velozes nas práticas sociais, políticas e econômicas. Precisamos nos adaptar à velocidade dessas transformações, ou seja, entender e aprender a lidar com o novo todos os dias: usar um novo gadget tecnológico, entender como funciona a mais nova rede social (da qual não podemos ficar de fora), gerenciar novas configurações no trabalho e nas estruturas hierárquicas corporativas, lidar com conflitos que surgem a partir do contato com novas gerações ou com outras culturas num mundo cada vez mais globalizado, etc.

Neste contexto, o design surge para ajudar o indivíduo a entender e lidar com este mundo. $O$ design deve auxiliar na constituição de um mundo sensível e concreto que reflita a lógica dos nossos tempos e, consequentemente, da sociedade atual. "O design se coloca entre o homem e a natureza como instrumento mediador capaz de adequar o cenário ambiental aos seus requerimentos básicos de vida com qualidade e bem-estar" (SOUZA, 1997: 40). Neste sentido, ele deve refletir o ambiente contemporâneo, trazendo propostas que facilitem sua existência e convívio social, ao organizar informações, elementos e materiais numa determinada ordem. De acordo com Frascara (2006: 23), design "é coordenar uma grande lista de fatores humanos e técnicos, transportar o invisível em visível, e comunicar. Design implica em planejar para obter um propósito específico

1 “Diseñar es coordinar una larga lista de factores humanos y técnicos, trasladar lo invisible en visible, y comunicar". perseguido". ${ }^{1}$

Um dos campos do design é o chamado design gráfico, convencionado como a área que engloba os trabalhos visuais que são reproduzidos em larga escala e podem ser definidos como "a seleção e organização de elementos visuais - letras, palavras, desenhos, ilustrações, fotos - para o formato impresso ou para qualquer outro meio semelhante de reprodução de imagem." (SOUZA, 1995: 173). Esse tipo de atividade integra três elementos que, segundo Frascara (2005: 21) definem o campo específico do design gráfico: 1) um método de design ou planejamento de uma estratégia comunicacional; 2 ) um objetivo de comunicação (o que dizer para as pessoas ou segmento de pessoas selecionadas como o público relevante da estratégia comunicativa) e 3) um meio específico de difusão, o meio visual de expressão das mensagens de comunicação.

Por meio dessa perspectiva mais ampla da comunicação, a atuação do designer gráfico é diversificada, englobando a concepção e produção de projetos gráficos para informação (sistemas de sinalização urbana e pública, projeto e diagramação de publicações, apresentação visual de informações quantitativas, desenho de instruções, mapas, etc.), para persuasão (sistemas de identidade visual, de rótulos e embalagens, campanhas de mídia impressa, campanhas de utilidade pública), projetos para educação (desenvolvimento de materiais educativos e interativos) e projetos para administração (desenho de formulários, boletos de transportes, tíquetes de espetáculos, organogramas, apresentação de comunicações empresariais internas, etc.) (FRASCARA, 2005: 103-120). Isso sem falar em todas as possibilidades a partir de suportes digitais, que ampliam cada vez mais as aplicações do design gráfico, com o uso de novos recursos e tecnologias. 
As funções que tais produtos de design gráfico exercem na sociedade são, igualmente, variadas e abrangem desde necessidades subjetivas de expressão até a amplificação da palavra escrita e falada em comunicações de abrangência internacional. Do ponto de vista pragmático, os signos gráficos de comunicação se estruturam em três tipos básicos de sistemas, conforme as funções sociais que têm possibilidade de desempenhar: os estéticos, que permitem o compartilhamento de reações emotivas sobre o mundo; os comportamentais, que regulam as relações sociais cordiais, entre os indivíduos membros de comunidades e os lógicos, por meio dos quais se torna possível a aquisição e o compartilhamento de conhecimentos, a modalização de comportamentos prescritos ou proibidos socialmente e, por último, a amplificação da língua através de códigos alternativos de natureza gráfica (AICHER; KRAMPEN, 1979: 14).

Entre os signos gráficos de comunicação com função sócio-prática, isto é, com função de regular o comportamento de pessoas no ambiente, situamse os pictogramas que, por meio de imagens simplificadas, reforçam o sentido de mensagens verbais ou as traduzem de um modo mais "divertido", emotivo, que colabora com sua rápida e correta interpretação por parte dos usuários/ receptores/atores sociais.

Os pictogramas nos falam por meio de formas e cores que, independentes dos sons falados, representam figuras reconhecíveis do mundo sensível, figuras-tipo, por meio das quais assumem a missão de comunicar mensagens completas, como frases ou sentenças inteiras, seja para indicar uma direção, um serviço, explicar um procedimento operativo ou alertar um risco que deve ser evitado. Apresentam como características principais: a busca por uma universalidade comunicativa, ou seja, se apresentam como signos autoexplicativos que podem ser compreendidos pelo maior número de pessoas; a densidade semântica e a concisão gráfica que, conjugadas, caracterizam a procura pela forma visual que possa trazer o máximo de informação com o mínimo de elementos ou rebuscamentos estéticos. (SOUZA, 2010: 14-17).

${ }^{2} \mathrm{O}$ desafio foi proposto durante uma aula do curso do Programa de Pós-Graduação em Ciências da Comunicação, sob responsabilidade da Profa. Dra. Sandra Souza, na ECA-USP, durante segundo semestre letivo de 2011. Os alunos participantes (Claudia Dayé, Fábio Amancio, Guilherme Ranoya S. Lins, Milton Raposo Jr., Raphael Tavares da Silva e Silvio Koiti Sato) foram estimulados a observar o entorno e assinalar mensagens que poderiam ser melhor resolvidas com o uso de imagens em substituição ou como reforço da palavra escrita.Entre várias opções, os alunos elegeram os frequentes avisos sobre higiene e uso coletivo saudável presentes nos banheiros da Unidade de Ensino como motivo do exercício de tradução gráfica de mensagens verbais.

${ }^{3}$ Banheiros de unidades de ensino da Universidade de São Paulo, campus Pinheiros, São Paulo, especialmente os da Escola de Comunicações e Artes, unidade frequentada pelos autores do exercício.
Presentes em várias situações cotidianas, nas etiquetas de roupas, nas telas de computadores, celulares e outros dispositivos móveis de comunicação, em equipamentos de uso doméstico, na sinalização de edifícios públicos, em mapas e guias turísticos, nas indicações de uso obrigatório, os pictogramas regulam o fluxo de pessoas em ambientes públicos e orientam o comportamento socialmente adequado no uso de diferentes equipamentos urbanos, com rapidez, objetividade e sem muito esforço prévio de aprendizagem. Desse modo, os pictogramas são versáteis para desempenhar o lado social do design visual gráfico urbano.

Exatamente por essa vocação pragmática e social, eles foram escolhidos pela equipe de autores como o tipo de signo gráfico que melhor se adequaria ao desafio proposto ${ }^{2}$ de traduzir uma mensagem verbal em discurso imagético com a finalidade de melhorar uma deficiência percebida no ambiente próximo.

Neste artigo, iremos descrever o processo criativo desenvolvido pela equipe de autores-comunicadores na busca por uma solução visual que pudesse substituir com uniformidade gráfica e sem muita dependência de legendas verbais, as mensagens impressas em vários banheiros de Unidades de ensino público ${ }^{3}$, diversas em suas formulações retóricas, mas semelhantes no apelo à adoção de medidas salutares comuns de higiene e asseio pessoal para o uso coletivo ordenado de ambientes públicos.

O método percorrido e a evolução na busca de uma solução capaz de ser entendida pela maior parte de usuários trouxe à tona a discussão de três tópicos que foram avaliados, pela equipe, como os mais relevantes do processo de design nos tempos atuais: a) o uso social do design; b) o centramento do projeto em necessidades do usuário e c) equilíbrio entre racionalidade e emoção na solução 
${ }^{4}$ Frascara (2006: 95-96) nomeia estas fases da seguinte maneira: 1 Encomenda ou briefing do projeto, 2- coleta de informações, 3- segunda definição do problema, 4- especificação do desempenho do design, 5terceira definição do problema, 6- desenvolvimento do anteprojeto, 7- apresentação ao cliente, 8organização da produção, 9- supervisão da implementação e 10- avaliação (tradução livre dos autores).

5 “Mirar no es un acto pasivo. No miramos para ver: miramos para entender, y para encontrar lo que queremos".

${ }^{6}$ Frequentadores do Departamento de Relações Públicas da Escola de Comunicações e Ates da USP, São Paulo. de design. À medida que descrevemos o desafio, não apenas estético, mas também comunicativo, de traduzir em imagens a mensagem exibida na foto eleita como mensagem exemplar - apresentaremos a síntese da discussão em torno dos três tópicos relacionados: design social, centrado no usuário, e com ênfase em aspectos emocionais de impacto e interação.

\section{O processo do design gráfico}

De acordo com Frascara (2006: 95-113), a metodologia e o planejamento das estratégias de comunicação, visualização e produção de produtos de design, normalmente, apresenta uma sequência de passos que, mesmo dependente da complexidade de cada problema envolvido, se mantém constante dentro da lógica de entender o que o cliente ou situação demanda; pesquisar e obter informações pertinentes; analisar as informações com foco na demanda; desenvolver uma resposta como solução do problema apresentado pelo cliente ou situação; obter aprovação do projeto para finalizar a solução em termos técnicos; implementar solução e monitorar resultados comparando-os com os objetivos estabelecidos. Estas fases metodológicas, embora possam variar em extensão e complexidade, representam uma atitude mental de disciplina no enfrentamento de questões que exigem soluções práticas, sejam elas de design, publicidade ou de comunicação visual de modo geral, o que não significa, de modo algum, excluir ou abafar do processo criativo, os componentes lúdicos ou afetivos da busca ${ }^{4}$.

O trabalho parte de uma solicitação (necessidade e especificações da demanda), passa por revisões da problemática a partir da coleta de informações adicionais que contextualizam a demanda, segue para a o desenvolvimento e apresentação da proposta e é finalizado com a ação, isto é, a materialização e monitoramento da proposta concretizada.

Pelos passos descritos nesta metodologia, é possível ressaltar novamente a importância do contexto na percepção do design, o que acarreta implicações na geração de significados por parte do interpretador. "Olhar não é um ato passivo, não olhamos para ver: olhamos para entender, e para encontrar o que queremos." ${ }^{5}$ (FRASCARA, 2006: 67). Portanto, podemos concluir que dois pontos são os mais importantes para obtermos atenção: significado e relevância.

Igualmente, é preciso levar em conta o entendimento de questões importantes a serem solucionadas pelo designer gráfico: é preciso que o design seja claro na forma e no conteúdo, que utilize estímulos atraentes e, sobretudo, considere o contexto cultural, social, econômico, tecnológico e ecológico do projeto. $\mathrm{Na}$ prática, as etapas da metodologia de um projeto de design são influenciadas por características específicas de cada situação e contexto.

Neste artigo, nos propomos a apresentar o processo de desenvolvimento de uma sequência pictográfica para orientar os usuários de uma determinada comunidade ${ }^{6}$ sobre a utilização adequada de banheiros públicos e substituir avisos como o da Figura 1 e 2, tomado aqui como exemplar da categoria:

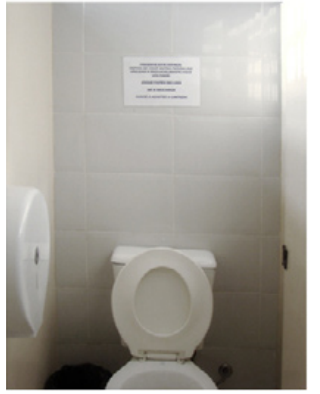

Figura 1: Sinalização em banheiro público

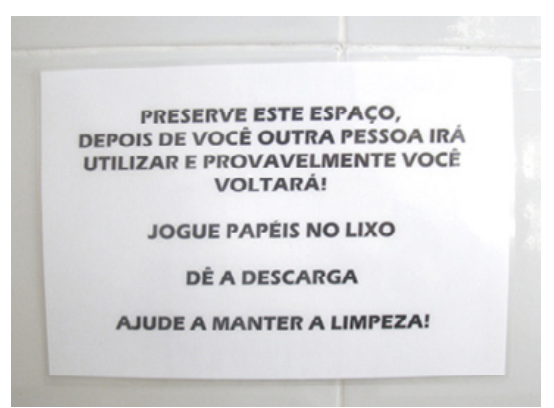

Figura 2: Detalhe da mensagem fixada 
A sinalização textual consiste numa folha de formato A4 plastificada e contém cinco mensagens, das quais quatro são imperativas (preserve, jogue, dê e ajude). Percebemos a utilização de um texto introdutório de sensibilização, ressaltando o aspecto comunitário do ambiente e também a recorrência de uso. Na sequência, temos duas orientações para a ação (jogar papéis no lixo e dar a descarga). A conclusão da mensagem é feita com uma frase para despertar a atenção. $O$ texto, composto na sua totalidade em letras maiúsculas, também colabora na tentativa de "gritar" e chamar a atenção para as mensagens de alerta e diretivas.

Para elaborar uma proposta de melhoria nesta sinalização, o passo inicial foi entender quais mensagens deveriam estar presentes no ambiente para contribuir com o seu bom funcionamento comunitário. Após avaliar os passos, etapas e ações dos indivíduos nesse espaço, percebemos que além das duas mensagens presentes no cartaz original, havia a necessidade de outras duas a fim de completar as orientações relacionadas não só ao uso do vaso sanitário (1. Não jogue papel no vaso; 2 . Use a descarga), mas também ao uso da pia (3. Lave as mãos; 4 , Jogue o lixo no cesto). Essa avaliação ilustra as fases inicias do processo de design, em que um dado projeto (em nosso caso, um exercício proposto como interferência visual, gráfica, no ambiente cotidiano visando uma situação preferível) é redefinido pelos designers a partir da coleta de informações sobre o problema em si, sobre os usuários e outros fatores incidentes. A redefinição do problema por meio da análise e interpretação dessas informações permite que o desempenho do design e o impacto que se quer obter junto aos usuários/consumidores sejam especificados com precisão antes mesmo da seleção de estilos, formatos e argumentos persuasivos. Em nosso caso, o problema redefinido nos levou a pensar em um conjunto de mensagens visuais que, a um simples olhar, pudessem fazer os usuários de banheiros coletivos da Universidade se lembrarem de hábitos recomendados para manutenção da limpeza, higiene e bem-estar coletivo. Igualmente, nos levou a escolher a sinalização por meio de pictogramas como estratégia de design, uma vez que priorizamos a informação - e não a persuasãocomo o caminho a ser seguido. Vale também ressaltar que a identificação desses espaços em ambientes como restaurantes, clubes, aeroportos, entre outros, por meio de símbolos gráficos, já se tornou assunto de curiosidade entre internautas e curiosos em torno do mundo, fato este que consideramos como favorável para gerar a atenção dos usuários às quatro mensagens selecionadas.

E por que banheiros como espaço de interferência? Quase sempre envolvidos em tabus, o uso desses espaços, que são conhecidos por diferentes nomes - toilete, lavatório, mictório, sanitário, water-closet ou WC, "transcende raça, religião, idade e classe social" (GREGORY; JAMES, 2006: 6) e possibilita uma análise cultural e sociológica das populações e comunidades em torno do mundo, revelando graus diferentes de desenvolvimento e tecnologias, inclusive as relativas à informação.

Com essas diretrizes iniciais definidas, a equipe partiu para a pesquisa iconográfica do conjunto de elementos utilizados na sinalização de banheiros públicos. Coletamos um conjunto de imagens e sistemas de sinalização (195 fotos), que foi classificado nas seguintes categorias: pictogramas que sinalizam e indicam a localização de banheiros públicos, representações de vasos sanitários, imagens que simbolizam cestos de lixo e papel, de mãos e água e, finalmente, sequências pictógraficas de orientação para uso de banheiros públicos. O conjunto iconográfico coletado foi arquivado pelo grupo no endereço eletrônico <http:// www.flickr.com/photos/crp5217/> "galeria crp5217" do site de compartilhamento de imagens e fotos Flickr, do Yahoo.

A pesquisa de imagens nos ajudou a definir novamente o desafio inicial em termos de design e de produção. Qual é o tipo mais universal de assento sanitário? Em que ângulo de visão sua expressão visual é reconhecida mais fácil e corretamente? As ações humanas precisam da figura completa do homem para serem visualizadas 
${ }^{7}$ Milton Raposo assumiu a responsabilidade de traduzir em imagens as decisões da equipe no desenvolvimento do projeto. ou basta apenas uma parte do corpo? Que parte? A mão, por exemplo? Pensando nestas questões, o designer do grupo ${ }^{7}$ desenvolveu as primeiras propostas visuais que pudessem sinalizar as mensagens, considerando forma e conteúdo e, também, canal de difusão e tecnologia de reprodução (Figuras 3 e 4).

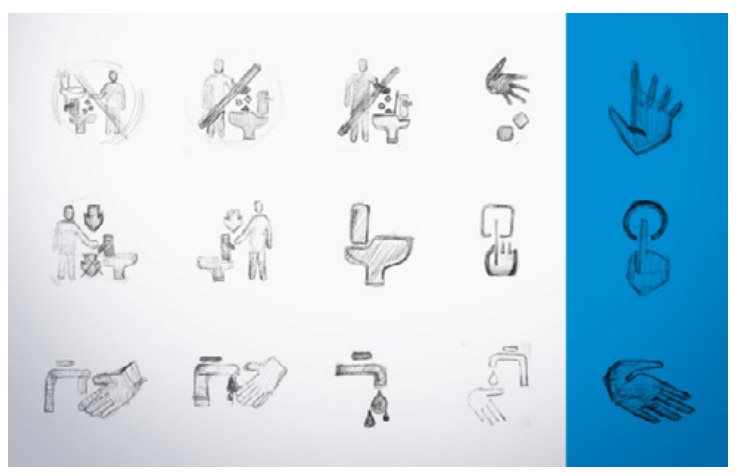

Figura 3: Esboços

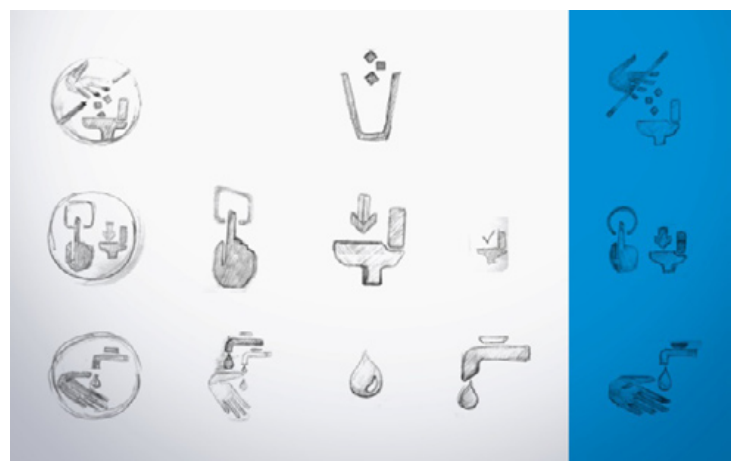

Figura 4: Esboços

Durante apresentação interna dos esboços aos integrantes da equipe, um elemento visual destacou-se como gerador de unidade à criação de um sistema de sinalização: a mão humana, presente em todas as mensagens que queríamos transmitir. Foi então criado um "alfabeto das mãos" que pudesse visualizar ações como jogar/não jogar, apertar botão para acionar equipamento e lavar-se. (Figura 5).

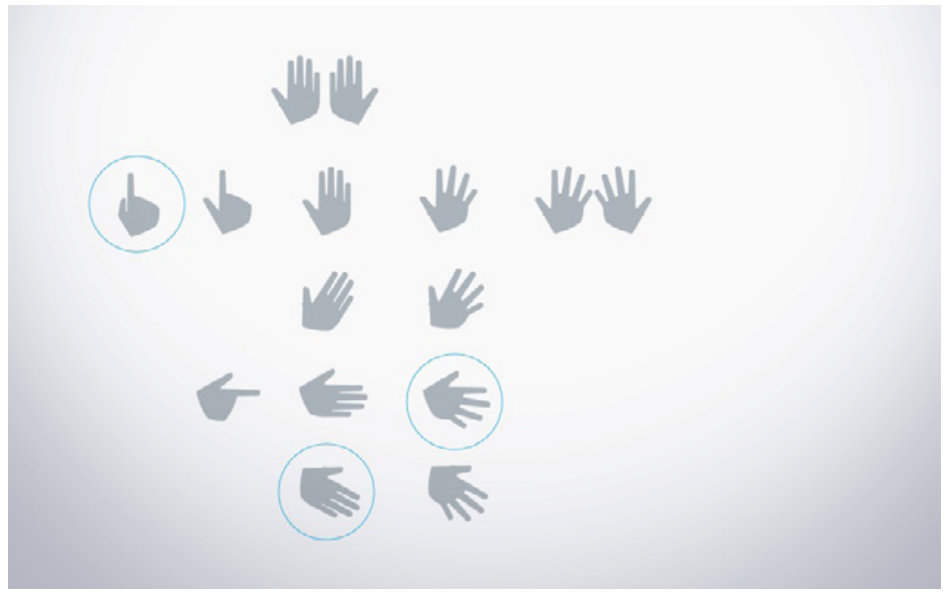

Figura 5: Sistema de mãos (variações de posições)

O passo seguinte foi inserir os demais elementos com os quais cada uma das posições de mãos iria interagir a fim de transmitir cada uma das mensagens específicas (Figura 6). 


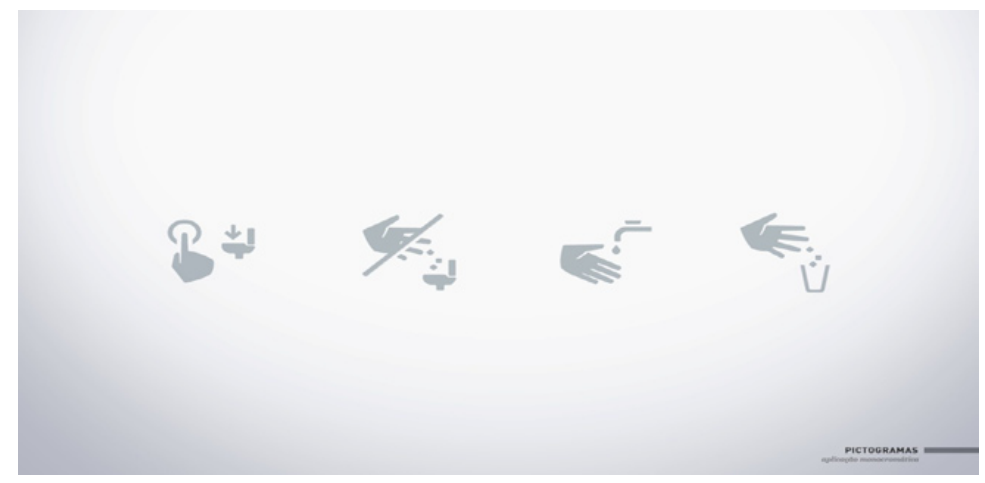

Figura 6: Primeira versão do desenho de mãos e elementos específicos das quatro mensagens selecionadas como mais relevantes.

Finalmente, foram inseridos os textos-legenda que apoiam e reforçam a mensagem desejada (Figura 7), completando o sistema de pictogramas proposto para a comunicação das mensagens desejadas nesse espaço.

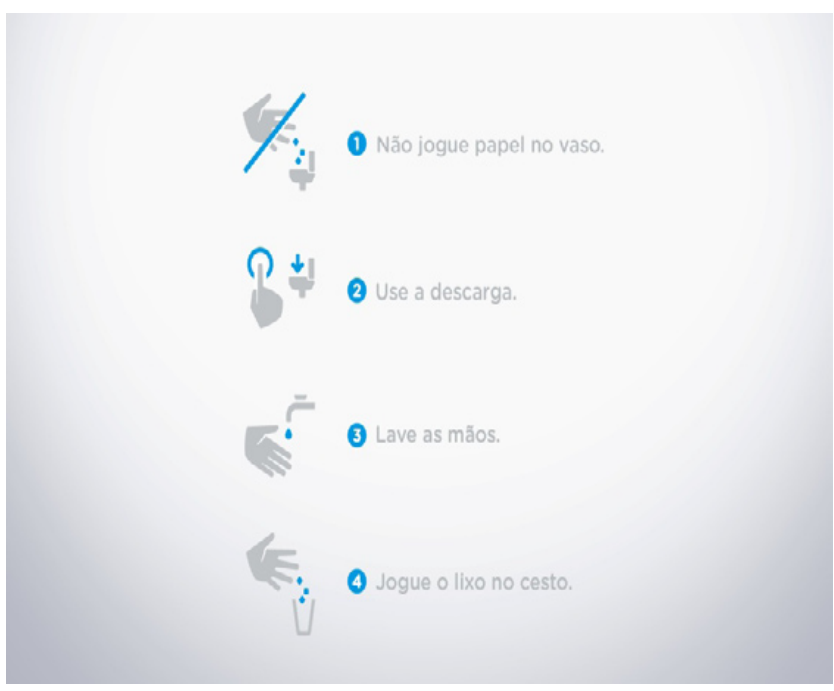

Figura 7: Pictogramas e textos de apoio.

Mesmo com os conteúdos e figuras definidas, o processo de desenvolvimento do design enfrentou a necessidade de redesenhos, sobretudo da mensagem negativa (Não jogue papel no vaso) e daquela em que a mão, para ser visível, teve que assumir uma escala diferente do objeto de interação (Use a descarga), para neutralizar ao máximo as possibilidades de interpretação ambígua ou incorreta.

Sabemos que a consulta a usuários, nesta fase de desenho, é indispensável para efetividade do projeto, porém, devido à exiguidade de tempo, não foi possível realizá-la durante a elaboração dos desenhos; a opção da equipe foi se antecipar às possíveis dificuldades dos usuários como produtores de sentido e mediadores críticos e, com a melhor versão sintático-semântica em mãos, colocamos protótipos em dois banheiros da Escola, para observação da reação dos usuários nas duas semanas subsequentes.

\section{Processo criativo e desenvolvimento do desenho}

É importante destacar que - apesar de parecer racional e super ordenado nessa explanação que fizemos anteriormente - o processo criativo desse conjunto inicial de pictogramas foi completamente caótico e não linear. A pesquisa inicial de elementos visuais que entrariam na composição gráfica dos pictogramas, somada à tentativa de se transformar as ações pretendidas em símbolos, aconteceram praticamente ao mesmo tempo e não existiu uma ordem predefinida para a criação de um ou outro pictograma em específico. 
Vários esboços foram desenvolvidos buscando-se um tipo de linguagem visual consistente, simples e sintaticamente compacta. Buscamos criar representações gráficas de superfície e, na criação dos pictogramas, tentamos fixar as mesmas características gráfico-visuais e os mesmos valores gráficos para linhas, cantos e cortes, que são algumas das variáveis visuais de tratamento sintático.

Até a mão humana ser percebida como um possível elemento-chave na criação de uma sequência pictográfica, alguns esboços e vários rascunhos foram feitos aleatoriamente. Quando de fato decidimos utilizar o sistema de mãos humanas com várias posições de dedos para representar as ações que precisávamos transformar em linguagem pictográfica, percebemos que aí começou de fato o processo de organização da informação coletada e a consequente vetorização de alguns dos elementos visuais que se mostravam sintaticamente melhor resolvidos.

Inicialmente criamos os pictogramas nas cores cinza claro e ciano, mas durante o aperfeiçoamento dos desenhos, com base nas percepções, discussões e considerações feitas pelo grupo, naturalmente adotamos um tipo de representação de superfície chapada na cor preta (100\% Black).

No pictograma "Lave as mãos" (Figura 8), a mudança mais nítida foi na forma da água, que deixou de ser uma gota e passou a ser representada por duas linhas contínuas paralelas - o que mostra a continuidade do fluxo saído da torneira.

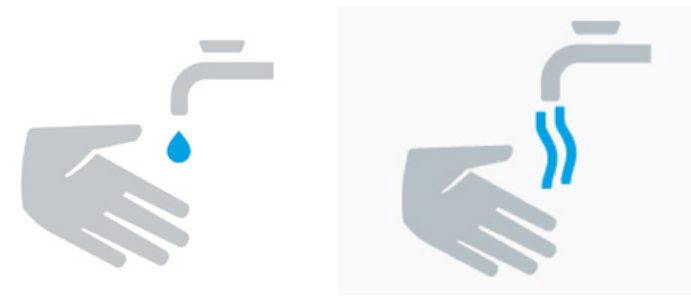

Figura 8: Evolução do pictograma "Lave as mãos"

${ }^{8}$ Internatitonal Organization for Standardization. ISO 7001:2007, Graphical symbols - Public information symbols. Third edition. 2007-11-01.

Symbol PI FF 027 "trash box or litter bin or rubbish bin".
No pictograma "Jogue o lixo no cesto" (Figura 9), a a textura do cesto foi mudada, assim como o lixo jogado pela mão. Segundo a normalização internacional (norma ISO $7001^{8}$ ), o símbolo gráfico destinado a indicar o descarte de lixo é composto pela vista frontal de uma figura humana, quatro losangos representativos de resíduos descartados e o contorno externo de um receptáculo de lixo, mas para acentuarmos a ação substituímos a figura humana pela mão aberta e destacamos sua proporção; reduzimos os detritos para três e utilizamos a textura de um engradado para indicar a lixeira pois esta representação gráfica se aproxima mais da forma das lixeiras utilizadas no ambiente.
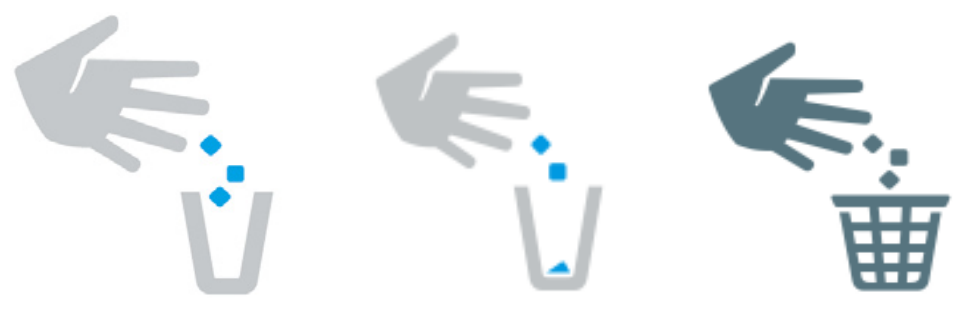

Figura 9: Evolução do pictograma "Jogue o lixo no cesto"

No pictograma "Não jogue papel no vaso" (Figura 10), foram feitos ajustes na forma do papel descartado e do vaso sanitário, assim como na barra de negação que indica a proibição da ação para maximizar a área útil dos elementos gráficos e evitar possíveis desvios de interpretação (instrumento de corte ferindo os dedos). 

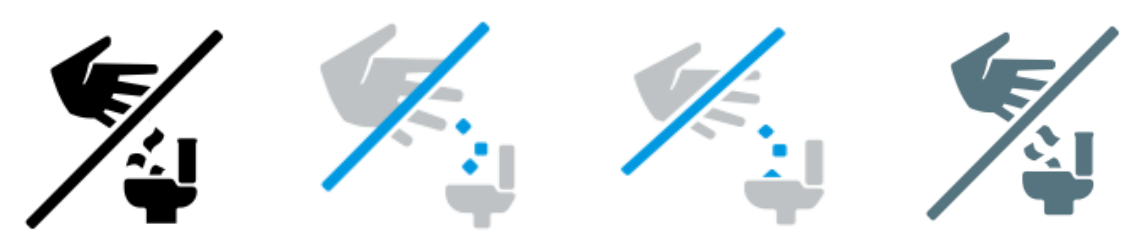

Figura 10: Evolução do pictograma "Não jogue papel no vaso"

Finalmente no pictograma "Dê a descarga após o uso do vaso" (Figura 11), discutimos mudanças nas formas tanto do vaso sanitário como na posição e forma dos indicadores da ação "apertar botão da descarga", visando integração mais harmônica dos três elementos (mão, seta e vaso) que se complementam na sintaxe do pictograma.

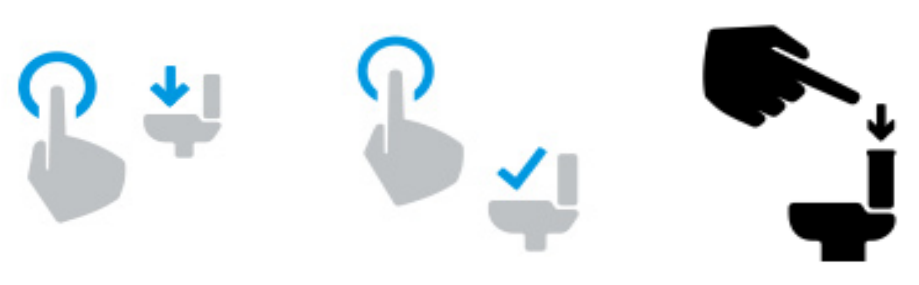

Figura 11: Evolução do pictograma "Use a descarga"

\section{Cognição e emoção na comunicação visual}

O uso de imagens, pictogramas e esquematismos, na tentativa de proporcionar uma comunicação visual capaz de reforçar ou mesmo, em muitos casos, substituir uma comunicação verbal, se pautou no princípio da racionalidade e objetividade como fundamentos para orientar o desenho e grande parte o processo criativo descrito acima.

Boa parte das ciências isolou a emoção de qualquer contato com práticas que deveriam ser tratadas objetivamente e isto se deve a um equívoco, perpetuado por séculos que opõe razão e emoção, como se fossem feitas de substâncias opostas, ou como explica Donald Norman, "Herbert Read acreditava que precisaríamos de uma teoria mística para ligar a beleza e a função. Bem, foram precisos cem anos, mas atualmente temos uma teoria, baseada em biologia, neurociência e psicologia, não em misticismo." (NORMAN, 2004: 40). O autor enfatiza que durante muito tempo pensamos na emoção como "um problema que devia ser superado pelo pensamento racional lógico." (Ibid: 38).

Sabemos hoje que ela é parte indissociável do processo cognitivo e que, sem ela, a leitura/cognição objetiva e racional do mundo ficaria totalmente comprometida. A emoção é um dos mais importantes reguladores deste sistema, que por sua vez condiciona não somente como entendemos uma mensagem, mas igualmente como respondemos ao seu estímulo; segundo Damásio (2005: 43):

“Ações eficazes requerem a companhia de imagens eficazes. As imagens permitem-nos escolher entre repertórios de padrões de ação previamente disponíveis e otimizar a execução da ação escolhida - podemos, de modo mais ou menos deliberado, mais ou menos automático, passar em revista mentalmente as imagens que representam diferentes opções envolvidas em uma ação, diferentes cenários, diferentes resultados da ação. Podemos selecionar a mais apropriada e rejeitar as inconvenientes. As imagens também nos permitem inventar novas ações a serem aplicadas a situações inéditas e fazer planos para ações futuras - a capacidade de transformar e combinar imagens de ações e cenários é a fonte da criatividade." 
De maneira simples, sem precisar destilar todos os mecanismos e saberes da neurociência atual, podemos resumir o funcionamento da emoção sobre nosso entendimento de sinais, informações e situações como sintetiza Norman (2004: 38): "Emoções, nós agora sabemos, mudam a maneira como a mente humana soluciona problemas - o sistema emocional muda a maneira como o sistema cognitivo opera. [...] as emoções auxiliam na tomada de decisão".

Basicamente o que Norman afirma, em plena afinidade a Damásio e outros neurocientistas, é que estados emocionais que nos causam relaxamento ou felicidade, influenciam nosso sistema cognitivo no sentido de ampliar a gama de entendimentos ou relações de significação, enquanto estados emocionais que nos causam aflição, ameaça ou angústia, fazem com que a produção de padrões mentais seja mais restrita e focada em imagens diretamente associadas ao que estamos lidando, tentando proporcionar padrões mais eficientes para o entendimento, reação e solução aos problemas que enfrentamos.

Estas descobertas interferem de maneira considerável na forma como lidamos (ou deveríamos lidar) com o design de informação. A primeira condição observada por Norman é que a estética (ou mais claramente as questões plásticas como a beleza e forma) retomam lugar equiparável à função no design quando entendemos que é ela a responsável por causar respostas emocionais: "objetos atraentes fazem as pessoas se sentirem bem, o que por sua vez faz com que pensem de maneira mais criativa." (NORMAN, 2004: 39). Norman é incisivo ao afirmar que objetos atraentes e belos são considerados, sistematicamente, mais fáceis de usar: não porque iludem os nossos sentidos, mas porque criam uma relação afetiva (estado emocional) que influencia nosso sistema nervoso a ampliar entendimentos e possibilidades interpretativas; com isto, nos predispomos mais facilmente a entender como o objeto funciona ou o que está nos comunicando, ao invés de tentarmos enquadrá-lo a nossa maneira, como desejamos que funcione ou como queremos que nos comunique. Da mesma forma, quando precisamos fazer uso de um objeto que nos causa irritação, frustração, ou desgosto, e não conseguimos entendê-lo ou operá-lo corretamente, repetimos insistentemente o mesmo procedimento acreditando que em uma das tentativas aquilo que esperamos dele, irá acontecer... normalmente, sem sucesso. Neste caso, a ausência de afeição provoca a restrição na busca de significados ou entendimentos; não exploramos opções, não temos insights, não respondemos criativamente à situação. Agimos de maneira estreita, repetitiva, imediata, buscando uma única solução, um entendimento que seja mais eficiente e objetivo... e ficamos presos nele.

A segunda condição observada pelo psicólogo cognitivo é especialmente importante quando criamos projetos de informação: sabendo que as emoções possuem estes efeitos sobre a cognição, Don Norman nos faz atentar para a maneira como devemos tratar o projeto quando lidamos com situações onde sabemos que os usuários estarão em uma situação estressante:

"quando as pessoas estão ansiosas, ficam mais concentradas, assim quando for esse o caso, o designer deve prestar atenção especial para se assegurar de que todas as informações necessárias à realização da tarefa estejam continuamente disponíveis, facilmente visíveis, com respostas claras e não ambíguas sobre as operações que o aparelho estiver realizando. Os designers podem escapar impunes sem sofrer cobranças ou críticas se o produto for divertido e prazeroso. Os objetos feitos para serem usados em situações estressantes exigem muito mais cuidado, e muito mais atenção ao detalhe." (NORMAN, 2004, p.47)

Portanto, a criação de peças gráficas que busquem comunicar ou instruir algo, dentro de um contexto prazeroso ou fazendo uso de uma linguagem divertida - obviamente, quando isto é possível - podem esperar de seus usuários maior imaginação, menos resistência ao entendimento e esforço necessário para 
responder aos estímulos dados. Foi esta premissa que nos levou a traduzir a mensagem verbal afixada nos banheiros públicos da ECA em imagens pictográficas, esteticamente mais afins aos gostos e valores dos estudantes de comunicações e artes.

No entanto, quando tratamos de situações de risco, informações técnicas de operação e instruções que não podem ser realizadas de maneira errada, é preciso considerar que esse usuário, provavelmente em situação de stress, irritação ou angústia, não terá a devida paciência para imaginar, supor ou interpretar a informação e não receberá bem quaisquer tipos de mensagens ou estímulos que não sejam apresentados de forma clara, precisa, objetiva e amplamente legível.

No caso dos pictogramas para o contexto analisado, espera-se que o uso de imagens em detrimento as mensagens verbais crie exatamente o vínculo afetivo... uma empatia, que pode colaborar com o engajamento dos usuários de banheiros da Universidade a seguirem as regras propostas, que diga-se, são verbalmente impositivas, e que por esta única condição já causariam certa resistência (ainda que o objetivo seja nitidamente o bem comum).
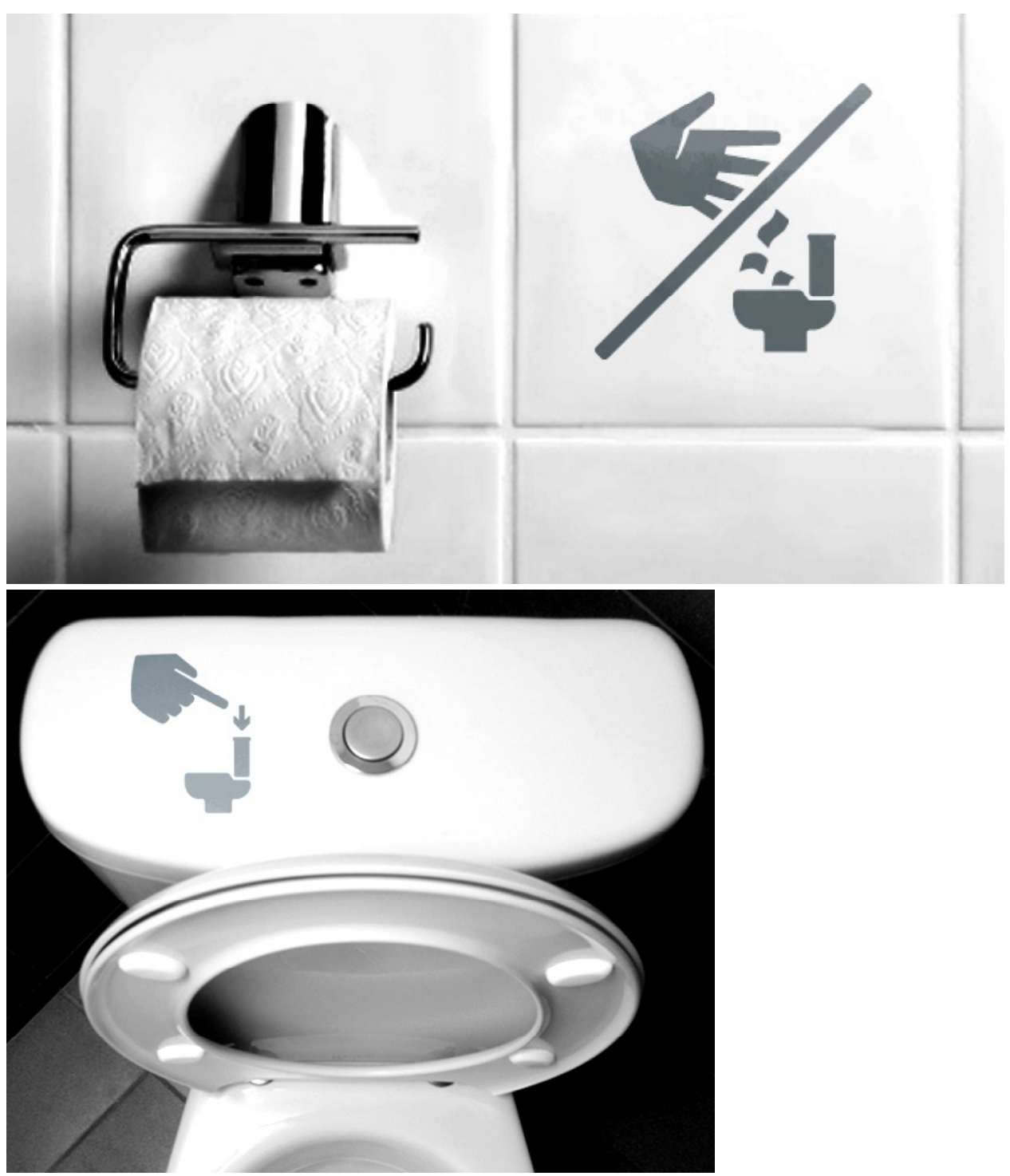

Figura 12: Adesivação individual de alguns equipamentos com símbolos gráficos sem legenda, para exemplificar proposta de informação visual.

\section{A avaliação dos pictogramas.}

Uma vez discutidos e redesenhados em versão final, ou melhor, "preferível", os pictogramas referentes às quatro mensagens (Não jogue papel no vaso; dê a descarga; jogue o lixo no cesto e lave as mãos) foram produzidos em impressão 
plastificada e em adesivos para serem colocados, experimentalmente, em dois banheiros, um feminino e outro masculino, do prédio do CRP - Departamento de Relações Públicas, Propaganda e Turismo da ECA. Os pictogramas foram aplicados à altura dos olhos, nos espaços próximos a pia e dentro dos boxes, em alturas $\mathrm{e}$ locais de fácil visualização.

A sequência pictográfica que utilizamos nos testes em banheiros públicos da ECA/USP segue apresentada abaixo:

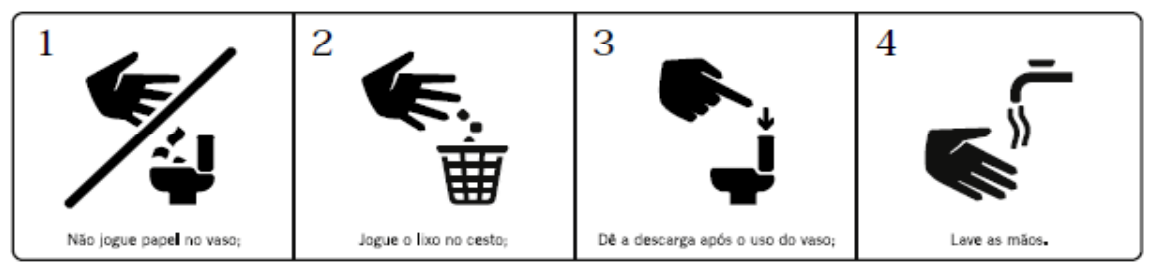

Figura 13: Sequência pictográfica para ambientes de banheiros públicos.
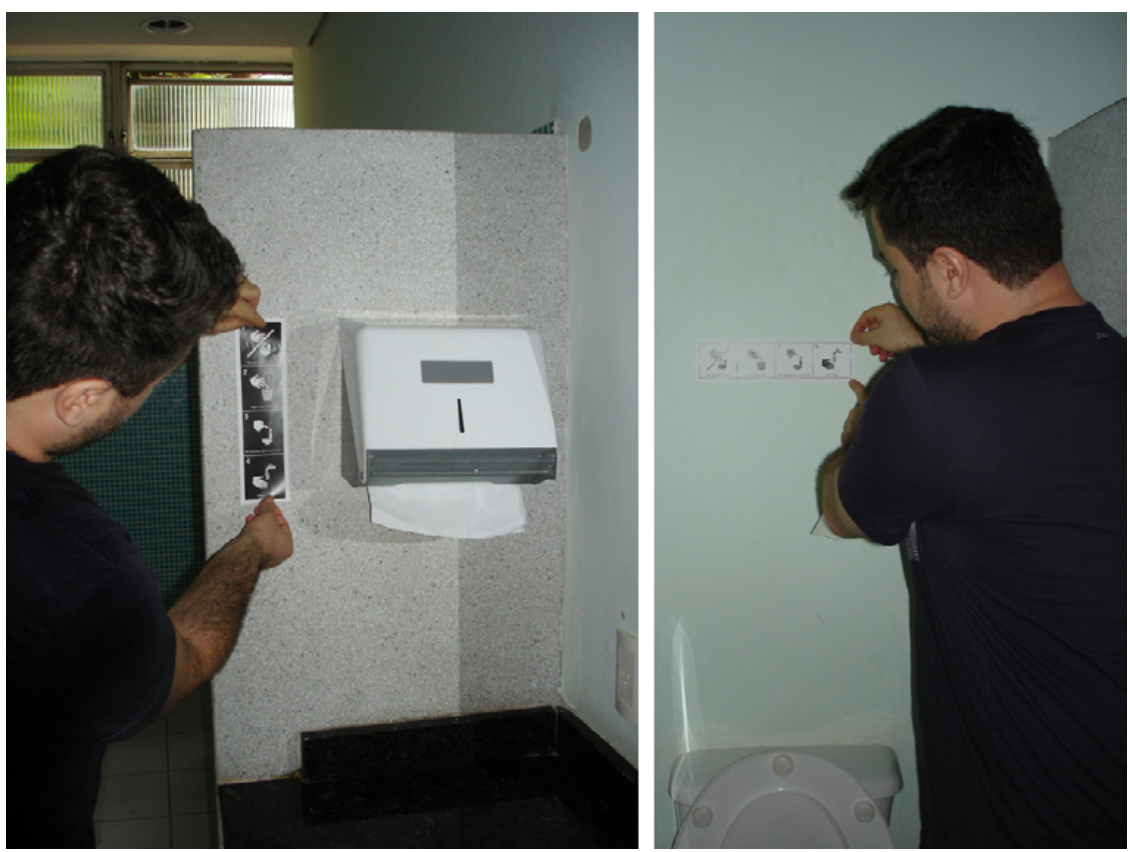

Figura 14: Registro fotográfico da afixação dos pictogramas (versões vertical, horizontal) nos banheiros masculino e feminino do CRP da ECA-USP em 30 de novembro de 2011.

Após a implementação das sinalizações nos banheiros selecionados, comunicamos a proposta e os objetivos desejados às pessoas responsáveis pela manutenção e limpeza dos banheiros, para que fosse feita uma observação sobre a eficácia dessa sinalização na prática. Após um período de sete dias, conversamos com aquelas que mais do que ninguém anseiam por uma melhoria do uso desse espaço público: as responsáveis pela limpeza cotidiana dos espaços citados.

Em entrevista realizada após sete dias da aplicação dos cartazes e adesivos pictografados, questionamos as limpadoras sobre as impressões que tiveram do uso dos banheiros durante esta semana experimental. A primeira verificação foi que no banheiro masculino alguns adesivos foram retirados, permanecendo apenas alguns dentro dos boxes. No feminino, todos permaneceram intactos no lugar que foram afixados.

As responsáveis pela limpeza relataram que papéis comumente não são depositados corretamente no cesto de lixo. Não foi apontada melhora nos itens "dar a descarga" e "não jogar papel no vaso". O item "lavar as mãos" não havia como ser mensurado. 
As ocorrências relatadas foram diversas, como a presença de urina fora do vaso sanitário, tanto no banheiro masculino como o feminino. Foram relatados casos de vasos entupidos, marcas de pé nas tampas do vaso sanitário (elas afirmam que os usuários usam o pé para abrir e fechar a tampa do assento sanitário). Também comentaram que, entre o público feminino, algumas usuárias utilizam papel para tocar nas maçanetas, evitando o contato com qualquer equipamento dentro do banheiro. A partir dessas informações, pode-se levantar a hipótese de que o usuário considera o ambiente sujo, e que não se dispõe a preservar o espaço com os procedimentos elementares, não querendo tocar na descarga, se aproximar do cesto de lixo e garantir que os resíduos sejam descartados adequadamente. Enfim, não adotam comportamentos colaborativos.

Questionamos as funcionárias sobre suas impressões em relação à sinalização aplicada. Ambas consideraram a sinalização clara em comunicação. "Até nós, que somos semi-analfabetas entendemos, qualquer um entende. Os sinais explicam exatamente como se deve fazer; eles não entendem porque não querem", disse uma das funcionárias. Outro comentário das entrevistadas foi que, na sua presença, os usuários têm mais cuidado e atenção com a limpeza e o correto uso dos banheiros.

A partir desses relatos, podemos constatar os seguintes pontos:

1. A sequência de pictogramas parece ter uma grande eficiência de comunicação da mensagem no aspecto semântico. As imagens cumprem seu papel em transmitir a informação, mostrando uma clara e detalhada descrição do como fazer.

2. O público não teve uma percepção da "nova sinalização" e, aparentemente, não houve empatia com a proposta. Podemos levantar a hipótese de que a sinalização não se coadunou com a cultura local da ECA. É possível que uma comunicação mais persuasiva e menos informativa, baseada em transgressão bem humorada, afetasse mais positivamente as emoções dos alunos dos espaços pela familiaridade de linguagem.

3. A avaliação dos pictogramas não se conclui uma vez que eles não foram, até este momento, suficientemente percebidos. Outra possibilidade para ampliar visibilidade e dirigir a atenção do usuário para a ação do momento, seria ampliar os pictogramas e colocá-los, isoladamente, em locais estratégicos: o pictograma "jogue o lixo no cesto" perto do grande cesto de lixo, ao lado das pias, por exemplo, e o pictograma "não jogue papel no vaso", bem acima de cada lixo colocado nos boxes. Dessa forma, o usuário não seria impactado com quatro mensagens ao mesmo tempo.

\section{Considerações finais}

A experiência descrita aqui mostra o desenvolvimento de um processo gráfico tal qual conceituado no início deste artigo: o design deve refletir o ambiente contemporâneo, trazendo propostas que facilitem sua existência e convívio social, ao organizar informações, elementos e materiais numa determinada ordem.

Não podemos deixar de ressaltar que as declarações feitas pelas funcionárias revelam nos pictogramas um poder de síntese e compreensão que abrangem diferenças e culturas. De certo modo, a síntese de cada elemento gráfico, correspondendo a referentes como papel, água e torneira, compostos com uma determinada gramática e aliados a legendas sucintas e práticas, formou uma sequência gráfica leve e facilmente compreensível.

Com a finalidade de agir como um reforço, buscamos a empatia do usuário, excluindo as informações de ênfase e solicitação de colaboração, tornando a 
mensagem suave e não impositiva, onde o usuário, membro de um público composto majoritariamente por universitários, pudesse identificar-se com a leveza e o aspecto clean, numa comunicação afetiva que exprime relaxamento, limpeza e bem-estar, sem entretanto ignorar suas mensagens práticas.

Porém, segundo observação do comportamento em uma semana experimental, a sequencia pictográfica estabeleceu pouco contato com esse público, o que poderia ser revertido mediante uma nova caracterização do processo de design, sobretudo nas fases finais do processo de acordo com Frascara (2006: 96): organização da produção final, supervisão da implementação (com maior número de banheiros adesivados ) e avaliação monitorada por tempo mais longo. Ou seja, do ponto de vista funcional, poderíamos reimplantar o produto de design com nova abordagem, aproveitando sua reflexão estética e aprofundando a reflexão de comunicação, para se entender os desafios na percepção do usuário. $\mathrm{Na}$ outra ponta, poderíamos adotar uma implementação planejada, calculando quantidades, tamanho, frequência, prazo e outras variantes, para que o design seja visto dentro das premissas em que foi criado.

Acreditamos que a tradução visual de mensagens verbais, apesar desses desafios a serem superados, se apresenta com extensas possibilidades comunicativas e sociais, imensamente útil na vida pública e cotidiana, orientando pessoas diferentes numa comunicação ágil e precisa.

\section{Referências Bibliográficas}

AICHER, O.; KRAMPEN, M. Sistemas de signos en la comunicación visual. Barcelona: Gustavo Gili, 1979.

BAUDRILLARD, J. O sistema dos objetos. São Paulo: Perspectiva, 2009.

BAUMAN, Z. Globalização: as consequências humanas. Rio de Janeiro: Jorge Zahar Ed., 1999.

. Modernidade líquida. Rio de Janeiro: Jorge Zahar Ed., 2001.

CASTELLS, M. A Sociedade em Rede. São Paulo: Paz e Terra, 1999.

COSTA, C. Questões de arte: o belo, a percepção estética e o fazer artístico. 2ª ed. São Paulo: Moderna, 2004.

DAMÁsıO, A. O Mistério da Consciência. São Paulo: Cia das Letras, 2005.

FRASCARA, J. Diseño Grafico Y comunicación. Buenos Aires: Infinito, 2005. . El Diseño de Comunicación. Buenos Aires: Infinito, 2006

GIDDENS, A. As consequências da modernidade. São Paulo: Unesp, 1991.

GREGORY, M.E.; JAMES, S. Toilets of the world. London: Merrell Publishers, 2006.

HALL, S. Identidade cultural na Pós-modernidade. Rio de Janeiro: DP\&A, 2000.

HARVEY, D. Condição pós-moderna. 14 ed. São Paulo: Loyola, 1992.

LIPOVETSKY, G. O império do efêmero: a moda e seu destino nas sociedades modernas. São Paulo: Companhia das Letras, 1989. 
MARANHÃO, J. A arte da publicidade: estética, crítica e kitsch. Campinas, SP: Papirus, 1988.

MASSIRONI, M. The psychology of graphic images: Seeing, Drawing, Communicating. London: Lawrence Erlbaum Associates, Publishers, 2002.

MCCRACKEN, G. Cultura e consumo: novas abordagens ao caráter simbólico dos bens e das atividades de consumo. Rio de Janeiro: MAUAD, 2003.

NORMAN, Donald. Design Emocional - Por que Adoramos (ou Detestamos) os Objetos do Dia-a-Dia. Rio de Janeiro: Rocco, 2004.

SOUZA, S. Conteúdo, forma e função no design de pictogramas. In: Correa, T. G., Org. Comunicação para Mercado: Instituições, Mercado, Publicidade, São Paulo: Edicon, p.171-192, 1995.

Design, Marketing, Comunicação. Revista Comunicações e Artes. São Paulo, 20 (30) 40-49, jan-abr.1997.

.Pictogramas Brasileiros. Um panorama do nosso jeito de designar conceitos. Tese de Livre-Docência apresentada à Universidade de São Paulo, Escola de Comunicações e Artes, São Paulo, 2010.

SUASSUNA, A. Iniciação à estética. 7ạ ed. Rio de Janeiro: José Olympio, 2005.

SUDJIC, D. A linguagem das coisas. Rio de Janeiro: Intrínseca, 2010.

Webliografia:

International Organization for Standardization. TC 145 Graphical Symbols. Disponível em : < http://www.iso.org/iso/standards_development/technical _ committees/list_of_iso_technical_committees/iso_technical_committee. htm?commid=52662 Acesso em: 20 mar. 2012.

Galeria de crp5217. Flickr do Yahoo. Disponível em: 〈http://www.flickr.com/ photos/crp5217/ Acesso em 20 mar. 2012. 